\title{
SUSTAINABLE LEVEL OF WATER PUMPING TO PROTECT ENVIRONMENT AND LIVESTOCK SUSTENANCE
}

\author{
Banshi Sharma, MSc. Vet. Sc. ${ }^{20}$
}

\begin{abstract}
Livestock production impacts heavily the world's water supply, accounting for more than 8 percent of global human water use, mainly for the irrigation of feed crops. Evidence suggests it is the largest sectoral source of water pollutants, principally animal wastes, antibiotics, hormones, chemicals from tanneries, fertilizers and pesticides used for feed crops, and sediments from eroded pastures. Continual water pumping may lead to the fall in water table and subsequently cause decrease vegetation and crop production, of which byproduct will be largely utilized for livestock feeding. This may result in unhygienic livestock watering management. Therefore, livestock number, production and livestock watering system must be harmonized to get optimum result.
\end{abstract}

\section{Introduction}

Livestock is an integral part of agricultural production system in Nepal and has a great biological diversity. Both intensive grazing and water quality protection programs are increasing the need for pumping water to livestock from locations where commercial electricity is not readily available. However, there may be instances where the distance from existing power lines to the desired pump location makes it cost-prohibitive to obtain electricity from the utility. A rule of thumb is that alternative energy sources may be economically justified if the distance to commercial power exceeds one-third of a mile. In this case, the livestock producer can select from a range of alternative power methods. The "best" alternative power option is generally site specific.

Prior to considering alternative power options, it is advisable to determine the cost of commercial electricity. This will allow comparison of the cost of commercial electricity to the cost of alternative systems such as solar or wind. If there is already electrical service within 1500 feet of the desired pumping location, it may be feasible to run a private electrical line to the site from the existing service. If the distance is greater, it is advisable to get a price quote from the local electrical utility regarding the cost. A new report from FAO (Spotlight, 2006) says livestock production is one of the major causes of the world's most pressing environmental problems, including global warming, land degradation, air and water pollution, and loss of biodiversity. Using a methodology that considers the entire commodity chain, it estimates that livestock are responsible for 18 percent of greenhouse gas emissions, a bigger share than that of transport. However, the report says, the livestock sector's potential contribution to solving environmental problems is equally large, and major improvements could be achieved at reasonable cost.

In addition to providing meat, milk, eggs, hides and skins, livestock provide draught power and manure to enhance soil fertility. Livestock form an integral part of the social fabric for many peoples while they serve as a capital reserve available for hard times. Urban arable land is limited and little room is left for livestock based on fodder crops (Annon, 1993).

\footnotetext{
${ }^{20}$ Senior Veterinary Officer. Department of Livestock Services, Harihar Bhawan.

Email : banshisharma@yahoo.com
} 
Intensive livestock keeping is the urgent need elsewhere for feeding ever increasing population in the world.

In spite of their growing global importance, livestock are increasingly being held responsible for many adverse effects on the environment. Loss of vegetative cover, reduced biodiversity, soil erosion and compaction, and excessive run-off often result from over-grazing. High concentrations of livestock contribute to contamination of ground water, eutrophication, and soil pollution. The processing of animal products in urban areas of developing countries especially generates waste materials creating disposal problems. Livestock can produce significant quantities of "greenhouse" gases (e.g. methane) thereby possibly contributing to global warming (Sharma B., 2003). Livestock and agriculture trends and concerns were identified by several stakeholders, including representatives from several donor agencies. A study led by the World Bank, FAO and USAID (Spotlight FAO, 2006) addressed these issues, according to the main livestock production systems practiced in the various regions of the world. Preserving natural resources for future generation is one of the major challenges due to overgrazing of the pastureland by livestock.

Livestock become compatible with the environment if they are raised with improved technology. The United Nations Environment Program estimates that since 1945 about 680 million hectares or 20 percent of the world's grazing lands have been significantly degraded (Sherchan, 2001). As well as implementing the measures above, improve protection of wild areas, maintain connectivity among protected areas, and integrate livestock production and producers into landscape management will protect biodiversity in greater extent.

It is thought that continual water pumping may lead to the fall in water table which subsequently causes reduce vegetation coverage in such a dry area that decreases in crop production, which byproduct will be largely utilized for livestock feeding. This may result in unhygienic livestock watering management. Therefore, livestock number, production and livestock watering system must be harmonized to get optimum result in Nepal as well.

\section{Required Watering Space, Flow Rate and Reserve Capacity}

There are two issues involved in providing adequate water for animals. First, the total water requirement (Table 1) must be met. But there is another issue-the water must be available when the animals want to drink it. If an adequate flow rate is available, then water can be supplied on demand. If, however, the flow rate is low, then storage capacity must be provided. Storage will facilitate supply of water whenever required by animals.

The rate of water intake and herd drinking pattern is dependent on the location of the water. If water is located outside the fenced pasture or paddock, such that the animals must leave the pasture area through an opening in the fenced area, the entire herd will tend to go for a drink at the same time. Dominant animals will drink first, leaving the timid animals to drink last. If sufficient flow rate or water capacity isn't present, the last to drink will suffer thirst. This herd drinking behavior has been observed even if the water source is only a few feet outside the pasture.

Table 1 Livestock water consumption for various animals

\begin{tabular}{|l|c|c|}
\hline Livestock & Avg. Consumption (gal/day) & Hot Weather (gal/day) \\
\hline Milking cow & $20-25$ & $25-40$ \\
\hline Dry cow & $10-15$ & $20-25$ \\
\hline Calves & $4-5$ & $9-10$ \\
\hline
\end{tabular}




\begin{tabular}{|l|c|c|}
\hline Buffalo bull & $8-12$ & $20-25$ \\
\hline Sheep & $2-3$ & $3-4$ \\
\hline Horse & $8-12$ & $20-25$ \\
\hline
\end{tabular}

Source : Lori Marsh (2001).

How Much Water Do You Need?

Actual consumption will depend on many factors including air temperature, animal size, species, age, milk production, type of ration, dry matter consumed, and other variables. Given the opportunity, milking cows will drink some water at the barn before and/or after milking. Provide at least 15 gal per hundred pounds of milk produced for each half day on pasture, especially if pastured during daylight hours.

\section{Sizing a Pump}

A pump must be capable of both delivering the required flow rate and overcoming the resistance inherent in the distribution system.

\section{Piping}

Galvanized steel, copper, and plastic are common pipe materials. Plastic pipe is made in flexible, semi-rigid, and rigid form. Flexible plastic pipe is commonly used in outdoor underground installations because of its ease and economy of installation. Also, for small diameters, flexible plastic pipe is the least expensive option. The most important consideration in designing a piping system is proper pipe sizing. In general, the right pipe size is a trade-off between a diameter that is small enough to minimize pipe cost and large enough to not result in excessive friction losses, which will increase the pumping energy and therefore pumping costs.

\section{Options for Powering a Watering System}

Several options are available when selecting a livestock watering system. The best system type for a particular producer will depend on many factors, including site layout, water requirement, availability and cost of water and electricity, and specifics of the water source, including type and location. Watering system can utilize one of the system which is available in low cost in particular area of the country. These are namely-

1. Gravity Systems

2. AC Electric Pumping Systems

3. Ram Pumps

4. Sling Pumps

5. Nose Pumps

6. Solar DC-Pumping Systems

7. Wind-Powered Systems

\section{Ground Water \& Animal Waste Management Systems}

The proper storage and land application of the waste produced at livestock feeding operations can be used as a viable fertilizer resource rather than a waste product for disposal. An added benefit of properly collecting and using this waste is reducing the chance of surface and ground water contamination. An oxygen depriving illness (methemoglobinemia) 
caused by drinking water with high levels of nitrate-nitrite may lead to serious and even fatal health effects in the elderly and the very young.

To prevent surface water contamination from feedlot runoff, a number of livestock producers have voluntarily or under regulatory requirements constructed animal waste management systems. These systems usually include at least one or more holding or storage ponds on the site. The ponds have been shown to be very effective in reducing contamination of streams and lakes.

If the ponds are located over permeable soils, such as sandy or gravelly soils, and are not lined with clay or there is failure of the liner, there is an increased risk of ground water contamination. This risk of ground water contamination occurs because all of the runoff from the lots is concentrated in a relatively small pond for a long period of time. Because of the weight of the liquid waste above the pond bottom, the risk of wastes leaking or leaching to the ground water greatly increases. Concerns arise because:

1) excessive leaching causes a loss of a valuable economic resource in the fertilizer value of the liquid waste, and 2) leaching may cause contamination of ground water, the owner/operator's water well or wells, or may impact the neighbors' wells. Once the ground water is contaminated, it is very costly to clean it up and return it to its natural quality.

Monitoring is required where ground water is of good quality and is present in sufficient quantity to be used. Monitoring is not required in areas where there is a thick layer of impermeable material (such as un weathered clay) between the land surface and the aquifer, since this would prevent the contaminants from reaching the ground water table. Site geology can vary widely, so each site must be reviewed on a case-by-case basis. Animal waste includes livestock and poultry manure, bedding and litter, plus such things as dairy parlor waste water, feedlot runoff, silage juices from trench silos and even wasted feed. These wastes can affect water quality if proper practices are not followed. These protective practices are very often referred to as best management practices (BMPs) and includes facilities or structures, management practices or vegetative cover.

Animal waste should be considered a valuable resource which, when managed properly, can reduce the need for commercial fertilizer. Such waste can add organic matter which improves water holding capacity and improves soil tilt. Animal waste can provide an economical source of nitrogen, phosphors and potassium as well as other nutrients needed for plant growth.

\section{Some best management practices (BMP's) follow}

- Store manure to allow timely applications and reduce nutrient losses from runoff.

- Use manure to reduce fertilizer cost.

- Apply manure to crops which can benefit from the nutrients.

- Avoid spreading near streams, wells, and ponds or sinkholes.

- Use conservation practices which minimize runoff and erosion on land where waste is applied.

- Calibrate application equipment.

- Incorporate manure into the soil.

- Analyze waste before spreading and soil test to balance nutrients to crop needs.

- Do not allow lagoons to overflow and collect runoff from concentrated animal operations for later land application to protect streams.

- Protect wetlands which serve to clean up water. 
- Add gutters to livestock housing and keep rainwater out of the waste stream.

- Divert runoff from land above the barnyard.

- Divert barnyard runoff away from streams and ponds.

- Add vegetated filter strips along streams to trap sediment and other pollutants.

- Exclude livestock from sensitive areas along stream banks and wetlands.

- Provide stream crossings and access for drinking.

- Collect and dispose of silage juices with the disposal system you use for manure.

- Use planned grazing in which two or more units are alternatively grazed and rested to improve forage production, maintain vegetative cover and retain waste on the land.

- Convert to livestock confinement systems such as dairy free stalls with flush gutters where all the waste is confined and recycled onto the land.

- Since most farms have fuel storage, check fuel storage tanks for spills and leaks and make sure your farm meets regulations.

- Use solids separation or settling basins to make liquid waste systems more liquid and easier to apply or recycle.

- Adapt new technology which is environmentally friendly such as composting poultry mortalities.

\section{Planning an Animal Waste Management System}

Planning proper waste handling will not only help protect the environment, it can improve the overall farming operation and overall cash flow. For example, dairymen who add free stalls not only provide for closed loop waste handling but also provide shade, feeding and loafing areas for the animals. These improvements translate into more milk (and easier management) which normally pays for the construction cost in 3 to 5 years. Adding cow mats in free stalls not only saves time and money but keeps the bedding in the stalls and out of flush gutters, making the liquid manure systems more manageable. Liquid manure systems are very popular, primarily because of the degree of automation. If solids are removed, the liquid waste is considerably easier to pump and recycle for flushing gutters.

Table 2. Annual Pounds of Nutrients in Manure as Excreted per 1000 Pounds Live weight

\begin{tabular}{|l|c|c|c|c|c|}
\hline & Dairy Cow & $\begin{array}{c}\text { Buffalo bull } \\
\text { Feeder }\end{array}$ & $\begin{array}{c}\text { Swine } \\
\text { Feeder }\end{array}$ & Laying Hen & Broiler \\
\hline Nitrogen, N & 150 & 124 & 164 & 263 & 423 \\
\hline $\begin{array}{l}\text { *Phosphate, } \\
\mathrm{P}_{2} \mathrm{O}_{5}\end{array}$ & 60 & 91 & 124 & 232 & 216 \\
\hline "Potash, $\mathrm{K}_{2} \mathrm{O}$ & 118 & 106 & 132 & 136 & 158 \\
\hline & *Elemental P \& K conversion can be made as follows: To convert P2O5 to elemental P, \\
multiply by 0.44; and to convert K2O to elemental K, multiply by 0.83 .
\end{tabular}

Large numbers of farm animals, requiring huge quantities of feed (grown on vast areas of land using massive inputs of water, energy, fertilizers and pesticides), produce enormous amounts of waste, causing serious pollution and environmental degradation.

\section{Large numbers of farm animals}

- billions of farm animals worldwide ( $36 \mathrm{~kg}$ annual per capita meat consumption)

- many animals are intensively reared in 'factory farms' 
- intensive livestock production responsible for $43 \%$ of the world's meat in 1996

\section{Requiring huge quantities of feed}

- $\quad$ one third of the world's cereal harvest is fed to farm animals

- $95 \%$ of US soya production (nearly 100 million tonnes per year) is used as feed

- worldwide, $73 \%$ of maize, $95 \%$ of oilmeals and $93 \%$ of fishmeal is fed to animals

- the EU imports $70 \%$ of the high quality protein used in animal feed, some from countries such as Brazil, Indonesia and Senegal where there is widespread poverty in human population.

\section{Grown on vast areas of land}

- two thirds of the world's agricultural land is used for maintaining livestock

Using massive inputs of water, energy, fertilizers and pesticides

- $87 \%$ of fresh water consumed worldwide is used for agriculture - the UN predicts that 40 countries will face severe water shortages in the next 20 years

- to produce $1 \mathrm{~kg}$ of grain-fed buffalo bull for meat purpose requires 100,000 litres of water (100 times and 50 times the amount required to produce $1 \mathrm{~kg}$ of wheat and $1 \mathrm{~kg}$ of rice respectively)

- feed production accounts for $70 \%$ of total fossil fuel use in animal farming

\section{Produce enormous amounts of waste}

- 1.4 billion tones of solid manure is produced by US farm animals per year - 130 times the amount produced by the human population

- 200 dairy cows produce as much nitrogen in their manure as 10,000 people

- farm animals are major sources of the greenhouse gases methane and nitrous oxide

- ammonia released from manure and slurry is a major contributor to acid rain

- intensive farms are major sources of airborne pollution and generate excess traffic, unpleasant smells and noise locally

\section{Causing serious pollution and environmental degradation}

- excess nitrogen from intensive farms may cause groundwater pollution, increasing nitrate levels in drinking water

- eutrophication (nutrient enrichment) of water systems can cause algal blooms killing fish and other aquatic life and "has become a major problem in north-west Europe" according to the European Environment Agency

- animal feeds crops such as Soya, maize and rapeseed are among the first to be genetically modified $(40 \%$ of the maize and $30-50 \%$ of the soybeans grown in the US are genetically modified) posing an unknown threat to the environment

\section{Conclusion}

Mixed farming is probably the most benign agricultural production system from an environmental perspective because it is, at least partially, a closed system. The waste products of one enterprise (crop residues), which would otherwise be loaded on to the natural resource base, are used by the other enterprise, which returns its own waste products (manure) back to the first enterprise. Because it provides many opportunities for recycling and organic farming and for a varied, more attractive landscape, mixed farming is the favorites system of many agriculturalists and environmentalists. 
Based on the most recent data available, Livestock's long shadow takes into account the livestock sector's direct impacts, plus the environmental effects of related land use changes and production of the feed crops animals consume. It finds that expanding population and incomes worldwide, along with changing food preferences, are stimulating a rapid increase in demand for meat, milk and eggs, while globalization is boosting trade in both inputs and outputs. In the process, the livestock sector is undergoing a complex process of technical and geographical change. Production is shifting from the countryside to urban and peri-urban areas, and towards sources of animal feed, whether feed crop areas or transport and trade hubs where feed is distributed. There is also a shift in species, with accelerating growth in production of pigs and poultry (mostly in industrial units) and a slow-down in that of cattle, sheep and goats, which are often raised extensively. Today, an estimated 80 percent of growth in the livestock sector comes from industrial production systems. Owing to those shifts, the report says, livestock are entering into direct competition for scarce land, water and other natural resources. Biotechnology seems to be the most promising way to ease land conflict between people and wildlife in the universe.

Livestock production also impacts heavily the world's water supply, accounting for more than 8 percent of global human water use, mainly for the irrigation of feed crops. Evidence suggests it is the largest sectoral source of water pollutants, principally animal wastes, antibiotics, hormones, chemicals from tanneries, fertilizers and pesticides used for feed crops, and sediments from eroded pastures. While global figures are unavailable, it is estimated that in the USA livestock and feed crop agriculture are responsible for 37 percent of pesticide use, 50 percent of antibiotic use, and a third of the nitrogen and phosphorus loads in freshwater resources. The sector also generates almost two-thirds of anthropogenic ammonia, which contributes significantly to acid rain and acidification of ecosystems(Sharma, 2004).

The sheer quantity of animals being raised for human consumption also poses a threat of the Earth's biodiversity. Livestock account for about 20 percent of the total terrestrial animal biomass, and the land area they now occupy was once habitat for wildlife. In 306 of the 825 terrestrial eco-regions identified by the Worldwide Fund for Nature, livestock are identified as "a current threat", while 23 of Conservation International's 35 "global hotspots for biodiversity" - characterized by serious levels of habitat loss - are affected by livestock production. Therefore, carrying capacity of land for animal and their sustainable level of water requirement must be assessed for friendly environment.

\section{REFERENCES}

1. Annon, 1993:, Livestock Master Plan, 1993.

2. Sherchand L., 2001:- Livestock and its relation to environment. Agriculture and environment, Communication issue. Ministry of Agriculture and Cooperatives, Singh Durbar, Kathmandu, Nepal. pp 52-57.

3. http://www.bae.uga.edu/extension/pubs/c827-cd.html

4. Lori M., 2001: Virginia Tech Publication Number 442-755, May 2001.

6. Sharma B. 2003: Role of improved livestock farming for preserving natural resources and limits the impact of climate change, Agriculture and Environment, pp 72-75.

7. Sharma B., 2004: Role of drug residue and drug resistant genes in livestock and their impact on human health and environment, Agriculture and Environment, pp 62-66.

8. Spotlight 2006 of FAO. 